\title{
Second and third year medical students' self-reported alcohol and substance use, smoking habits and academic performance at a South African medical school
}

\begin{tabular}{|c|c|}
\hline \multicolumn{2}{|c|}{$\begin{array}{l}\text { Authors: } \\
\text { Annelize Vorster }{ }^{1} \text { (D) } \\
\text { Anthonie M. Gerber }{ }^{1} \text { (D) } \\
\text { Lynette J. van der Merwe }{ }^{2} \text { (I) } \\
\text { Sanet van Zyl }{ }^{1} \text { (D) }\end{array}$} \\
\hline \multicolumn{2}{|c|}{$\begin{array}{l}\text { Affiliations: } \\
{ }^{1} \text { Department of Basic Medi } \\
\text { Sciences, Faculty of Health } \\
\text { Sciences, University of the } \\
\text { Free State, Bloemfontein, } \\
\text { South Africa }\end{array}$} \\
\hline \multicolumn{2}{|c|}{$\begin{array}{l}{ }^{2} \text { School of Medicine, } \\
\text { University of the Free State, } \\
\text { Bloemfontein, South Africa }\end{array}$} \\
\hline \multicolumn{2}{|c|}{$\begin{array}{l}\text { Corresponding author: } \\
\text { Anthonie Gerber, } \\
\text { gerberAM@ufs.ac.za }\end{array}$} \\
\hline \multicolumn{2}{|c|}{$\begin{array}{l}\text { Dates: } \\
\text { Received: } 05 \text { Dec. } 2017 \\
\text { Accepted: } 11 \text { July } 2019 \\
\text { Published: } 23 \text { Sept. } 2019\end{array}$} \\
\hline \multicolumn{2}{|c|}{$\begin{array}{l}\text { How to cite this article: } \\
\text { Vorster, A., Gerber, A.M., } \\
\text { Van der Merwe, L.J. \& } \\
\text { Van Zyl, S., 2019, 'Second- and } \\
\text { third-year medical students' } \\
\text { self-reported alcohol and } \\
\text { substance use, smoking habits } \\
\text { and academic performance } \\
\text { at a South African medical } \\
\text { school', Health SA Gesondheid } \\
24(0), \text { a1041. https://doi.org/ } \\
\text { 10.4102/hsag.v24i0.1041 }\end{array}$} \\
\hline \multicolumn{2}{|c|}{$\begin{array}{l}\text { Copyright: } \\
\text { (C) 2019. The Authors. } \\
\text { Licensee: AOSIS. This } \\
\text { is licensed under the } \\
\text { Creative Commons } \\
\text { Attribution License. }\end{array}$} \\
\hline \multicolumn{2}{|l|}{ Read online: } \\
\hline 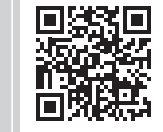 & $\begin{array}{l}\text { Scan this QR } \\
\text { code with your } \\
\text { smart phone or } \\
\text { mobile device } \\
\text { to read online. }\end{array}$ \\
\hline
\end{tabular}

Background: Health professional students frequently use alcohol and narcotics. The potential impact on academic performance and professional behaviour is concerning.

Aim: This study aimed to determine self-reported use of alcohol, illicit substances (e.g. cannabis, lysergic acid diethylamide [LSD], magic mushroom, cocaine, crack, ecstasy, methamphetamine and heroin), prescription medication and smoking habits, correlating academic performance.

Setting: Faculty of Health Sciences, University of the Free State.

Methods: An observational, descriptive, cross-sectional study design was used. Information was obtained using a self-administered questionnaire, capturing demographics, self-reported academic performance, drinking and smoking habits, and substance use. Coded responses were analysed using the Remark Office OMR 8 Software System. Descriptive statistics were calculated for categorical variables.

Results: Completed questionnaires comprised 171 students. A total of $78.4 \%$ of second year and $82.8 \%$ of third year students reported using alcohol. Twenty-two per cent of second year and $24.1 \%$ of third year students reported cannabis use. In the second year group, three $(2.7 \%)$ students reported using magic mushroom, two $(1.8 \%)$ reported cocaine, two (1.8\%) reported ecstasy and one $(0.9 \%)$ reported using methamphetamine. Only third year students reported using LSD or 'crack'. Cigarette smoking was common $-31.5 \%$ and $35.1 \%$ in both groups, respectively. Smokeless tobacco devices were used by $8.5 \%$ of second year and $7.1 \%$ of third year students. Almost $40 \%$ of both groups reported that they had smoked a water pipe. Academic performance achieved was mostly 60\% - 69\% (38.9\%) among second year students and 70\% - 79\% (46.6\%) among third year students.

Conclusion: Self-reported use of alcohol and drugs and smoking among medical students is alarming. Additional student support, early identification and referral for management and/ or rehabilitation should be a priority at tertiary institutions responsible for training future healthcare professionals.

Keywords: Alcohol; Drug abuse; Medical students; Smoking habits; Academic performance.

\section{Introduction}

\section{Background}

Alcohol abuse among students nationally and internationally is rising and alcohol has generally been identified as the most commonly used substance among students (SA Statistics 2013; Van Zyl et al. 2015). Hazardous drinking is defined by the volumes of alcohol consumed and/or the pattern of alcohol consumption associated with an increased risk for alcohol-attributable diseases in the future (Seggie 2012). Hazardous drinking has to be differentiated from alcohol use disorders, which have their own specific diagnostic criteria (Halme et al. 2008). According to data published by the National Institute on Alcohol Abuse and Alcoholism (NIAAA) (n.d.) in the USA, 80\% of students drink alcohol. These results indicated that half of the students engage in binge drinking, where men consume five drinks and women consume four drinks in the course of $2 \mathrm{~h}$.

Peltzer, Davids and Njuho (2011) have indicated that young adults have the highest levels of binge drinking and harmful drinking patterns in South Africa. O'Flynn (2011) defines harmful 
drinking where health problems develop because of alcohol consumption. This may include physical and/or psychological harm. A recent study by Van Zyl et al. (2015) at the University of the Free State focusing on alcohol consumption among all undergraduate students in residences found that $15.6 \%$ of students partake in hazardous drinking, $4.1 \%$ of students partake in harmful drinking and $5.6 \%$ of students are alcohol dependent. This is in line with data reported by international studies (Johnston et al. 2015).

Drug use among South African students and young adults is also alarmingly high (SA Statistics 2013; Van Zyl et al. 2015). According to SA Statistics (2013), at least $7.06 \%$ of the South African student population reportedly use some form of narcotic. A study conducted by Choi et al. (2011) at Weill Cornell Medical College in both New York and Qatar found that more than one-third of medical students reported excessive drinking and 5.0\% reported non-prescription steroid use. The literature suggests that medical students abuse prescription drugs more commonly in comparison to students in general. This statement has, however, not been substantiated scientifically. International studies have found that lifetime use of both cocaine and amphetamines, used as tranquilisers during the last 30 days, occurred at considerably higher rates among medical students (Mesquita, Laranjeira \& Dunn 1997; Van Zyl et al. 2015). Students have the perception that by using psychostimulants, they will enhance their concentration and ability to study (Bucher, Vu \& Hojat 2013; Habibzadeh et al. 2011), even when it has not been prescribed to them by a medical practitioner, for example, in the case of attention deficit/hyperactivity disorder (ADHD). Medical students involved in previous studies have 'justified' their use of drugs, claiming that their scientific knowledge of the effects of illegal substances protect them from developing drug-related problems (Borsari \& Carey 2001; Mesquita et al. 1997).

The driving factors for students' drinking behaviour and substance use include peer pressure, social activities and external factors (Levy \& Earleywine 2003; Van Heerden et al. 2009). In a study conducted among medical students in Spain, Mesquita et al. (1997) identified competitiveness, heavy workloads, contact with patients and the proximity of the residency examination as contributing factors to drug use. The emotional toll and responsibility when dealing with patients as part of daily routine training and as part of their clinical examinations cause students to rely on drugs in order to cope under these circumstances. This was also found in a South African study conducted by Gerber, Botes and Vorster (2016).

\section{Aim of the study}

Data regarding alcohol and substance use and its effects on academic performance among medical students in South Africa are lacking. This study aimed to determine selfreported alcohol and smoking habits and substance use as well as self-reported academic performance in second and third year medical students at a South African medical school.

\section{Research methods and design}

This was an observational, descriptive, cross-sectional study. It forms part of a larger study in a well-defined populationbased sample of adolescents and young adults in the Faculty of Health Sciences, University of the Free State (UFS). The target population included all second and third year undergraduate medical students, aged 18 years and older, registered in the Faculty's medical (MBChB) programme. These students are all involved in structured lectures presented by the School of Medicine and were willing to participate in a research project. First year students were excluded from this specific project in order to rule out possible other reasons or causes for using alcohol, other illicit drugs and/or smoking which might be specific to first year students only, for example, adjusting to a new social environment or adapting to the academic load and responsibilities. Medical students in their clinical years areagain exposed to different daily responsibilities and stressors in comparison to the preclinical years of studying. They were therefore not included in this study, but might be included in similar future studies.

Students were approached after a lecture. The principal investigators organised data collecting sessions with the presenting lecturer involved and were present at all times. The necessary information pertaining to the study and information regarding participation was given to the students at each of these sessions, whereafter they were free to choose to participate or not. Questionnaires were then handed to the participating students to complete individually at their own pace. Participation was voluntary and questionnaires were completed anonymously. Completed questionnaires were collected and kept safe for data collection and analyses by the investigators.

The questionnaire used in this study was compiled by using information from various internationally validated questionnaires, with Cronbach's alpha scores ranging between 0.74 and 0.90 (Bucholz et al. 1994; Center for Adolescent Substance Abuse Research 2009; Ialomiteanu \& Adlaf 2015; Mayer \& Filstead 1979; Wechsler et al. 1994). Careful attention was given to questionnaire design and questions applicable to South African students were grouped together. An initial group of 78 students voluntarily completed the questionnaire anonymously. Reviewing responses, results and data from this group, the questionnaire was deemed suitable for data collection as part of this study.

For the purpose of this study, information regarding demographic information, self-reported academic performance, drinking and smoking habits, and use of substances was obtained.

\section{Data analysis}

Responses from the questionnaires were coded. The investigators captured and analysed the data from the completed questionnaires using the Remark Office OMR 8 Software System. Descriptive statistics, including frequencies and percentages for the categorical variables, were calculated. 


\section{Ethical consideration}

Approval to conduct this research was obtained from the Health Sciences Research Ethics Committee of the Faculty of Health Sciences at the University of the Free State (ETOFS 243/15). This includes authorisation from the responsible and applicable academic, research and student bodies involved. Participants received an information leaflet and the principal investigators explained the research objectives to them. Confidentiality was assured as no identifying data were recorded. The participants gave written consent before questionnaires were handed out for completion during a scheduled contact session.

\section{Results}

\section{Demographic information}

A total of 171 students participated in the study. The response rate was $96.6 \%(113 / 117)$ for second year and $46.8 \%(58 / 124)$ for third year students. In the second year, participants were mostly females $(n=70,62.0 \%)$, whereas in the third year half of the participants were females $(n=29,50.0 \%)$.The age range for the second year students was between 19 and 26 years (77.0\% in the age group of 19-20 years).The age range for the third year students was between 19 and 25 years $(86.2 \%$ in the age group of 20-22 years).

\section{Use of prescription medication and other illicit drugs}

\section{Medication for attention deficit/hyperactivity disorder}

As shown in Table 1, 10 participants in both the second (9.3\%) and third (17.2\%) year groups, respectively, used prescribed medication for ADHD, while $12(10.7 \%)$ in the second year group and $10(17.2 \%)$ in the third year group used medication for ADHD without a prescription.

\section{Sedatives and tranquilisers}

There were six (5.4\%) and nine (8.2\%) second year students who reported using sedatives and tranquilisers with and without a prescription, respectively, while eight (13.8\%) and four $(6.9 \%)$ third year students reported using sedatives and tranquilisers with and without a prescription, respectively. These results are summarised in Table 2.

\section{Glue and other solvents}

Three $(2.7 \%)$ second year students and one (1.8\%) third year student reported using glue and other solvents over a period of 12 months.

\section{Synthetic cannabis and cannabis}

None of the second year students reported using synthetic cannabis ('spice'), while $14(24.1 \%)$ third year students reported its use. Twenty-five (22.3\%) second year and $14(24.1 \%)$ third year students reported cannabis use. This included $11(9.8 \%)$ second year and $5(8.6 \%)$ third year students who reported using cannabis between 3 and 39 times over a period of 12 months, and $1(0.9 \%)$ second year and $2(3.5 \%)$ third year students who reported using cannabis more than 40 times over a period of 12 months.

\section{Hardcore drugs}

In the second year group, three $(2.7 \%)$ students reported the use of magic mushroom, two $(1.8 \%)$ reported cocaine, two $(1.8 \%)$ reported ecstasy and one $(0.9 \%)$ reported methamphetamine use. None of the second year students reported lysergic acid diethylamide (LSD) or 'crack' use. In the third year group, one $(1.8 \%)$ student reported the use of magic mushroom, three (5.2\%) reported the use of cocaine, one $(1.8 \%)$ reported the use of ecstasy and two $(3.5 \%)$ reported the use of methamphetamine. Three (5.2\%) indicated the use of LSD and two (3.5\%) reported the use of 'crack'.

None of the second or third year students used ketamine, while one $(0.9 \%)$ second year student reported heroine and benzodiazepine use, respectively, between one and two times during the past 1 year.

\section{Drinking habits}

As shown in Table 3, a quarter of second year students (25.7\%) had their first drink at the age of 18 years and $22.4 \%$ of the third year students started drinking at the age of 16 years. On a typical day, $20.4 \%$ of the second year and $25.9 \%$ of the third year students stated that they would drink between two and three alcohol-containing drinks. Almost one-third of the second year $(n=34,30.1 \%)$ and $34.5 \%(n=20)$

TABLE 1: Prevalence of the use of prescription medication among second and third year medical students at the University of the Free State over a period of 12 months.

\begin{tabular}{|c|c|c|c|c|c|c|c|c|c|c|c|c|c|c|}
\hline \multirow[t]{3}{*}{ Medication } & \multicolumn{14}{|c|}{ Number of occurrences over a period of 12 months } \\
\hline & \multicolumn{2}{|c|}{$1-2$} & \multicolumn{2}{|c|}{$3-5$} & \multicolumn{2}{|c|}{$6-10$} & \multicolumn{2}{|c|}{ 11-19 } & \multicolumn{2}{|c|}{$20-39$} & \multicolumn{2}{|c|}{$\geq 40$} & \multicolumn{2}{|c|}{ Total } \\
\hline & $n$ & $\%$ & $n$ & $\%$ & $n$ & $\%$ & $n$ & $\%$ & $n$ & $\%$ & $n$ & $\%$ & $n$ & $\%$ \\
\hline \multicolumn{15}{|c|}{ Drugs for ADHD with prescription } \\
\hline Second year $(n=108)$ & 1 & 0.9 & 1 & 0.9 & 4 & 3.7 & 0 & - & 0 & - & 4 & 3.7 & 10 & 9.3 \\
\hline Third year $(n=58)$ & 2 & 3.5 & 1 & 1.7 & 2 & 3.5 & 0 & - & 0 & - & 5 & 8.6 & 10 & 17.2 \\
\hline \multicolumn{15}{|c|}{ Drugs for ADHD without prescription } \\
\hline Second year $(n=112)$ & 9 & 8.0 & 1 & 0.9 & 1 & 0.9 & 0 & - & 1 & 0.9 & 0 & - & 12 & 10.7 \\
\hline Third year $(n=58)$ & 3 & 5.2 & 2 & 3.5 & 2 & 3.5 & 1 & 1.7 & 2 & 3.5 & 0 & - & 10 & 17.2 \\
\hline \multicolumn{15}{|c|}{ Sedatives or tranquillisers with prescription } \\
\hline Second year $(n=111)$ & 2 & 1.8 & 0 & - & 1 & 0.9 & 1 & 0.9 & 0 & - & 2 & 1.8 & 6 & 5.4 \\
\hline Third year $(n=58)$ & 4 & 6.9 & 1 & 1.7 & 0 & - & 0 & - & 0 & - & 3 & 5.2 & 8 & 13.8 \\
\hline \multicolumn{15}{|c|}{ Sedatives or tranquillisers without prescription } \\
\hline Second year $(n=110)$ & 6 & 5.5 & 2 & 1.8 & 0 & - & 0 & - & 0 & - & 1 & 0.9 & 9 & 8.2 \\
\hline Third year $(n=58)$ & 2 & 3.5 & 1 & 1.7 & 0 & - & 0 & - & 0 & - & 1 & 1.7 & 4 & 6.9 \\
\hline
\end{tabular}

ADHD, attention deficit/hyperactivity disorder. 
TABLE 2: Prevalence of the use of other substances and illegal drugs among second and third year medical students at the University of the Free State over a period of 12 months.

\begin{tabular}{|c|c|c|c|c|c|c|c|c|c|c|c|c|c|c|}
\hline \multirow[t]{3}{*}{ Substances and illegal drugs } & \multicolumn{14}{|c|}{ Number of occurrences over a period of 12 months } \\
\hline & \multicolumn{2}{|c|}{$1-2$} & \multicolumn{2}{|c|}{$3-5$} & \multicolumn{2}{|c|}{$6-10$} & \multicolumn{2}{|c|}{$11-19$} & \multicolumn{2}{|c|}{ 20-39 } & \multicolumn{2}{|c|}{$\geq 40$} & \multicolumn{2}{|c|}{ Total } \\
\hline & $n$ & $\%$ & $n$ & $\%$ & $n$ & $\%$ & $n$ & $\%$ & $n$ & $\%$ & $n$ & $\%$ & $n$ & $\%$ \\
\hline \multicolumn{15}{|l|}{ Glue and other solvents } \\
\hline Second year $(n=110)$ & 3 & 2.7 & 0 & - & 0 & - & 0 & - & 0 & - & 0 & - & 3 & 2.7 \\
\hline Third year $(n=56)$ & 0 & - & 1 & 1.8 & 0 & - & 0 & - & 0 & - & 0 & - & 1 & 1.8 \\
\hline \multicolumn{15}{|l|}{ Synthetic cannabis ('Spice') } \\
\hline Second year $(n=112)$ & 0 & - & 0 & - & 0 & - & 0 & - & 0 & - & 0 & - & 0 & - \\
\hline Third year $(n=58)$ & 7 & 12.1 & 1 & 1.7 & 1 & 1.7 & 1 & 1.7 & 2 & 3.5 & 2 & 3.5 & 14 & 24.1 \\
\hline \multicolumn{15}{|l|}{ Cannabis } \\
\hline Second year $(n=112)$ & 13 & 11.6 & 6 & 5.4 & 2 & 1.8 & 3 & 2.7 & 0 & - & 1 & 0.9 & 25 & 22.3 \\
\hline Third year $(n=58)$ & 7 & 12.1 & 1 & 1.7 & 1 & 1.7 & 1 & 1.7 & 2 & 3.5 & 2 & 3.5 & 14 & 24.1 \\
\hline \multicolumn{15}{|l|}{ LSD } \\
\hline Second year $(n=113)$ & 0 & - & 0 & - & 0 & - & 0 & - & 0 & - & 0 & - & 0 & - \\
\hline Third year $(n=57)$ & 3 & 5.3 & 0 & - & 0 & - & 0 & - & 0 & - & 0 & - & 3 & 5.3 \\
\hline Second year $(n=113)$ & 3 & 2.7 & 0 & - & 0 & - & 0 & - & 0 & - & 0 & - & 3 & 2.7 \\
\hline Third year $(n=57)$ & 1 & 1.8 & 0 & - & 0 & - & 0 & - & 0 & - & 0 & - & 1 & 1.8 \\
\hline \multicolumn{15}{|l|}{ Cocaine } \\
\hline Second year $(n=113)$ & 2 & 1.8 & 0 & - & 0 & - & 0 & - & 0 & - & 0 & - & 2 & 1.8 \\
\hline Third year $(n=58)$ & 2 & 3.5 & 1 & 1.7 & 0 & - & 0 & - & 0 & - & 0 & - & 3 & 5.2 \\
\hline \multicolumn{15}{|l|}{ ‘Crack’ } \\
\hline Second year $(n=113)$ & 0 & - & 0 & - & 0 & - & 0 & - & 0 & - & 0 & - & 0 & - \\
\hline Third year $(n=58)$ & 2 & 3.5 & 0 & - & 0 & - & 0 & - & 0 & - & 0 & - & 2 & 3.5 \\
\hline \multicolumn{15}{|l|}{ Ecstasy } \\
\hline Second year $(n=112)$ & 1 & 0.9 & 0 & - & 1 & 0.9 & 0 & - & 0 & - & 0 & - & 2 & 1.8 \\
\hline Third year $(n=58)$ & 1 & 1.7 & 0 & - & 0 & - & 0 & - & 0 & - & 0 & - & 1 & 1.7 \\
\hline \multicolumn{15}{|l|}{ Methamphetamine } \\
\hline Second year $(n=113)$ & 1 & 0.9 & 0 & - & 0 & - & 0 & - & 0 & - & 0 & - & 1 & 0.9 \\
\hline Third year $(n=58)$ & 2 & 3.5 & 0 & - & 0 & - & 0 & - & 0 & - & 0 & - & 2 & 3.5 \\
\hline Third year $(n=58)$ & 0 & - & 0 & - & 0 & - & 0 & - & 0 & - & 0 & - & 0 & - \\
\hline \multicolumn{15}{|l|}{ Benzodiazepines } \\
\hline Second year $(n=113)$ & 1 & 0.9 & 0 & - & 0 & - & 0 & - & 0 & - & 0 & - & 1 & 0.9 \\
\hline Third year $(n=58)$ & 0 & - & 0 & - & 0 & - & 0 & - & 0 & - & 0 & - & 0 & - \\
\hline
\end{tabular}

LSD, lysergic acid diethylamide.

TABLE 3: Prevalence of the use of alcohol and related products among second and third year medical students at the University of the Free State over a period of 12 months.

\begin{tabular}{|c|c|c|c|c|c|c|c|c|c|c|c|c|c|c|}
\hline \multirow[t]{3}{*}{ Drinking habits } & \multicolumn{14}{|c|}{ Number of occurrences over a period of 12 months } \\
\hline & \multicolumn{2}{|c|}{$1-2$} & \multicolumn{2}{|c|}{$3-5$} & \multicolumn{2}{|c|}{$6-10$} & \multicolumn{2}{|c|}{ 11-19 } & \multicolumn{2}{|c|}{ 20-39 } & \multicolumn{2}{|c|}{$\geq 40$} & \multicolumn{2}{|c|}{ Total } \\
\hline & $n$ & $\%$ & $n$ & $\%$ & $n$ & $\%$ & $n$ & $\%$ & $n$ & $\%$ & $n$ & $\%$ & $n$ & $\%$ \\
\hline \multicolumn{15}{|l|}{ Alcohol } \\
\hline Second year $(n=111)$ & 17 & 15.3 & 9 & 8.1 & 16 & 14.4 & 10 & 9.0 & 10 & 9.0 & 25 & 22.5 & 87 & 78.4 \\
\hline Third year $(n=58)$ & 2 & 3.5 & 11 & 19.0 & 5 & 8.6 & 5 & 8.6 & 8 & 13.8 & 17 & 29.3 & 48 & 82.8 \\
\hline \multicolumn{15}{|c|}{ Energy drink with alcohol } \\
\hline Second year $(n=110)$ & 22 & 20.0 & 6 & 5.5 & 5 & 4.5 & 5 & 4.5 & 4 & 3.6 & 5 & 4.5 & 47 & 42.7 \\
\hline Third year $(n=57)$ & 8 & 14.0 & 8 & 14.0 & 5 & 8.8 & 3 & 5.3 & 1 & 1.7 & 3 & 5.3 & 28 & 49.1 \\
\hline \multicolumn{15}{|l|}{ Alcohol and cannabis } \\
\hline Second year $(n=113)$ & 12 & 10.6 & 5 & 4.4 & 0 & - & 0 & - & 1 & 0.9 & 0 & - & 18 & 15.9 \\
\hline Third year $(n=58)$ & 3 & 5.2 & 2 & 3.5 & 3 & 5.2 & 1 & 1.7 & 0 & - & 0 & - & 9 & 15.5 \\
\hline
\end{tabular}

of the third year students bought their alcohol from a liquor store.

\section{Alcohol}

A total of $87(78.4 \%)$ second year and $48(82.8 \%)$ third year students reported the use of alcohol. In the second year group, 10 (9.0\%) students reported using alcohol 20-39 times and $25(22.5 \%)$ students reported using alcohol more than
40 times in the previous year. In the third year group, there were $8(13.8 \%)$ students who reported using alcohol 20-39 times and 17 (29.3\%) students who reported using alcohol more than 40 times in the previous year.

\section{Combination of alcohol and energy drinks}

The use of alcohol combined with an energy drink was reported by 47 (42.7\%) second year and 28 (49.1\%) third year 
students in the past 1 year. Nine (8.1\%) second year students used an energy drink with alcohol between 20 and $\geq 40$ times. Four $(7.0 \%)$ third year students combined an energy drink with alcohol with a frequency of between 20 and $\geq 40$ times.

\section{Alcohol and cannabis}

Eighteen (15.9\%) second year and nine (15.5\%) third year students reported using cannabis and alcohol together. Only one $(0.9 \%)$ second year student reported using cannabis and alcohol together between 20 and 39 times over a period of 12 months, and none more than 40 times. None of the third year students reported using cannabis and alcohol more than 20 times over a period of 12 months.

\section{Smoking habits}

The participants' smoking habits are illustrated in Table 4. In both groups, almost one-third of students reported cigarette smoking over a period of 12 months. About 31.5\% $(n=35)$ of second year and $35.1 \%(n=20)$ of third year students reported cigarette smoking over a period of 12 months. Nine $(8.5 \%)$ second year and four (7.1\%) third year students reported using smokeless tobacco devices, and 45 (40.9\%) second year and $23(39.7 \%)$ third year students reported smoking a water pipe over a period of 12 months.

Fifteen $(13.3 \%)$ second year students reported that they had started smoking over a period of 12 months compared to the nine $(15.5 \%)$ participants in the third year group.

\section{Academic performance}

Table 5 summarises the participants' academic performance. One $(0.9 \%)$ of the second year and none of the third year students reported average marks between $90 \%$ and $100 \%$. In the second year group, $14.2 \%(n=16)$ of the students reported average marks of $80 \%-89 \% ; 25.7 \%(n=29)$ reported average marks of $70 \%-79 \%, 38.9 \%(n=44)$ reported average marks of
$60 \%-69 \%$ and $20.4 \%(n=23)$ reported average marks of $<$ $60 \%$. As far as the third year group was concerned, $8.6 \%(n=$ 5 ) of the students reported average marks of $80 \%-89 \%$; $46.6 \%(n=27)$ reported average marks of $70 \%-79 \%, 41.4 \%$ $(n=24)$ reported average marks of $60 \%-69 \%$ and $3.5 \%(n=2)$ reported obtaining marks between $50 \%$ and $59 \%$.

According to students' responses in the questionnaire, their self-perceived perception was that their social habits, including use of alcohol, drugs and/or smoking, did not negatively affect their academic performance.

\section{Discussion}

This study confirmed that the self-reported prevalence of the use of alcohol and other substances of abuse, as well as smoking, among a group of undergraduate medical students is similar to findings in international literature. All types of drugs and alcohol are becoming more easily accessible and are used by populations much younger than it was in the past (Arora et al. 2016; NIAAA 2006).In 2013, the United Nations Office on Drugs and Crime reported that approximately 167-315 million people across the world between the ages of 15 and 64 years use illicit substances.

In this study, methylphenidate use with and without prescription was higher among third year students than among second year students. A previous study among medical students across all 5 years of the MBChB curriculum at the UFS reported that $9.8 \%$ of students used methylphenidate, and about one-third of these students were diagnosed with ADHD. Most students reported using stimulants to improve their ability to study as well as academic performance (Ialomiteanu \& Adlaf 2015). Similar studies conducted at other South African medical schools found lifetime use of stimulants for non-medical purposes in approximately one-fifth of medical students, with only about $2 \%$ of these students diagnosed with ADHD (Jain et al. 2017; Retief \& Verster 2016; Steyn 2016). These findings reported by Webb, Valasek and

TABLE 4: Prevalence of the use of cigarettes and related products among second and third year medical students at the University of the Free State over a period of 12 months.

\begin{tabular}{|c|c|c|c|c|c|c|c|c|c|c|c|c|c|c|}
\hline \multirow[t]{3}{*}{ Smoking habits } & \multicolumn{14}{|c|}{ Number of occurrences over a period of 12 months } \\
\hline & \multicolumn{2}{|c|}{$1-2$} & \multicolumn{2}{|c|}{$3-5$} & \multicolumn{2}{|c|}{$6-10$} & \multicolumn{2}{|c|}{ 11-19 } & \multicolumn{2}{|c|}{ 20-39 } & \multicolumn{2}{|c|}{$\geq 40$} & \multicolumn{2}{|c|}{ Total } \\
\hline & $n$ & $\%$ & $n$ & $\%$ & $n$ & $\%$ & $n$ & $\%$ & $n$ & $\%$ & $n$ & $\%$ & $n$ & $\%$ \\
\hline \multicolumn{15}{|l|}{ Cigarettes } \\
\hline Second year $(n=111)$ & 14 & 12.6 & 6 & 5.4 & 4 & 3.6 & 2 & 1.8 & 2 & 1.8 & 7 & 6.3 & 35 & 31.5 \\
\hline Third year $(n=57)$ & 9 & 15.8 & 2 & 3.5 & 0 & - & 1 & 1.8 & 1 & 1.8 & 7 & 12.3 & 20 & 35.1 \\
\hline \multicolumn{15}{|l|}{ Smokeless tobacco } \\
\hline Second year $(n=106)$ & 4 & 3.8 & 2 & 1.9 & 3 & 2.8 & 0 & - & 0 & - & 0 & - & 9 & 8.5 \\
\hline Third year $(n=56)$ & 2 & 3.6 & 1 & 1.8 & 1 & 1.8 & 0 & - & 0 & - & 0 & - & 4 & 7.1 \\
\hline \multicolumn{15}{|l|}{ Water pipe } \\
\hline Second year $(n=110)$ & 14 & 12.7 & 12 & 10.9 & 9 & 8.2 & 1 & 0.9 & 4 & 3.6 & 5 & 4.5 & 45 & 40.9 \\
\hline Third year $(n=58)$ & 8 & 13.8 & 3 & 5.2 & 5 & 8.6 & 2 & 3.5 & 4 & 6.9 & 1 & 1.7 & 23 & 39.7 \\
\hline
\end{tabular}

TABLE 5: Second and third year medical students' current academic performance at the University of the Free State.

\begin{tabular}{|c|c|c|c|c|c|c|c|c|c|c|c|c|}
\hline \multirow[t]{3}{*}{ Year group } & \multicolumn{12}{|c|}{ Current academic performance } \\
\hline & \multicolumn{2}{|c|}{$90-100 \%$} & \multicolumn{2}{|c|}{$80-89 \%$} & \multicolumn{2}{|c|}{$70-79 \%$} & \multicolumn{2}{|c|}{$60-69 \%$} & \multicolumn{2}{|c|}{$50-59 \%$} & \multicolumn{2}{|c|}{$<50 \%$} \\
\hline & $n$ & $\%$ & $n$ & $\%$ & $n$ & $\%$ & $n$ & $\%$ & $n$ & $\%$ & $n$ & $\%$ \\
\hline Second year $(n=113)$ & 1 & 0.9 & 16 & 14.2 & 29 & 25.7 & 44 & 38.9 & 20 & 17.7 & 3 & 2.7 \\
\hline Third year $(n=58)$ & 0 & - & 5 & 8.6 & 27 & 46.6 & 24 & 41.4 & 2 & 3.5 & 0 & - \\
\hline
\end{tabular}


North (2013) are similar to the prevalence of methylphenidate use among medical students in the USA. Findings of a study conducted by Steyn (2016) at the University of Pretoria indicated a significant correlation $(p<0.001)$ between the use of methylphenidate and the rate at which alcohol, tobacco, cannabis, hard drugs and prescription medication were used.

The occurrence of drug use among the second and third year students was $7.2 \%$ and $12.2 \%$, respectively. These students reported using drugs such as magic mushroom, cocaine, ecstasy and methamphetamine, while five $(8.8 \%)$ third year students reported using LSD or 'crack'. Four (2.3\%) of the second and third year students also reported using glue and other solvents. Although these results are lower than figures reported in other international studies (Budhathoki et al. 2010; Drugwatch 2015), this reported risky behaviour in future healthcare professionals warrants intervention.

Alcohol use and abuse was seen to be very common in this group of students. The majority of second year (78.4\%) and third year (82.8\%) students reported using alcohol over a period of 12 months. Of concern was the reported alcohol use (more than 40 times over a period of 12 months) that was reported by $22.5 \%$ of second year and $29.3 \%$ of third year students. This is in line with international findings by Leinwand (2007), indicating an increase in the amount of alcohol consumed by students in general. In this group of students, $42.7 \%$ of second year and $49.1 \%$ of third year students reported using alcohol in combination with energy drinks, while $15.9 \%$ of second year and $15.5 \%$ of third year students reported a combination of alcohol and cannabis use.

Welcome et al. (2015) indicated that there are significant differences in academic performance among medical students who consume alcoholic beverages and those who totally abstain from it. In this study, although $78 \%-83 \%$ of students reported using alcohol and $23 \%-29 \%$ of students reported excessive alcohol use, students reported good academic performance. A total of $64.6 \%$ of second year and $87.9 \%$ of third year students reported obtaining marks between $60 \%$ and $79 \%$. Less than one-fifth of second year and only two third year students reported obtaining marks below 60\%. Alcohol use among the study participants does not seem to impact the academic performance as reported by students.

Fewer students reported smoking cigarettes than using alcohol, with approximately one-third of second and third year students reporting cigarette smoking. About $40 \%$ of second and third year students reported using a water pipe device, while less than $10 \%$ of second and third year students reported using smokeless tobacco devices. While cigarette smoking and tobacco use are detrimental to health, regular smoking is associated with other lifestyle choices and/or risky behaviours, such as drinking heavily, the use of cannabis and having multiple sexual partners (Emmons et al. 1998; Lejuez et al. 2003; Padrão et al. 2007; Rigotti, Lee \& Wechsler 2000).
Almost one-fifth of all second year and almost a quarter of third year students in this study reported smoking cannabis. The health hazards of cannabis use include the effect of over-activation in cerebral areas, leading to altered sensory perception, changed sense of time, mood changes, impaired body movement, difficulty with problem solving and thinking, and impaired memory (National Institute on Drug Abuse n.d.). The long-term effects of cannabis include impaired learning and memory function.

Students have reported stress, such as stress associated with dealing with patients, as one of the important factors influencing their use of alcohol and other substances. This finding is supported by a study conducted by Arora et al. (2016) among a group of 230 undergraduate and postgraduate medical students in India, where $72.4 \%$ of participants reported psychological stress as the most common reason for using substances, followed by the need to reduce tiredness $(46.8 \%)$ and peer pressure $(42.6 \%)$.

Academic performance was not categorically rated as poor, average or high for the purpose of this study. Conclusions were drawn based upon whether changes in academic performance were noted by the individual students, based upon their use of alcohol or other substances. Although participating students mostly reported no adverse effects, that is, any negative impact from previous results, on their academic performance associated with their alcohol and substance use or cigarette smoking, the results indicate poor habits and lifestyle choices that could affect not only future academic performance but also patient care. This is supported by findings regarding capabilities and function among medical students indicating that academic stressors and working conditions are not ideal (Gerber et al. 2016).The rigours of medical training may place students at higher risk for burnout, depression, and low mental and emotional quality of life, which may lead to alcohol abuse (Jackson et al. 2016).

Based on the high prevalence of alcohol use and cannabis and cigarette smoking reported in this study, as well as small numbers of students reporting the use of 'hardcore' drugs, it would be valuable to implement awareness and intervention programmes for undergraduate medical students. Students in the second and third year of the 5-year curriculum at this institution have limited exposure to patients during preclinical training. The impact of increased responsibility associated with exposure to patients in the clinical training environment could contribute to exacerbation of the unhealthy, dangerous habits reported in this student group in later years of study. It is therefore imperative to address the issue of alcohol and drug abuse (and unhealthy lifestyle choices) among undergraduate medical students in order to ensure that they are able to function without impairment as future healthcare professionals.

\section{Study limitations}

The response rate in the third year group was lower than expected because these students were preparing off campus for assessments at the time of completion of the questionnaires. 
Surveys may be biased because participants must recall past experiences. The self-reported and sensitive nature of the information gathered in this questionnaire may have inhibited students and contributed to bias in findings, in spite of assurances of confidentiality and privacy.

Participants may not have responded fully in fear of potential repercussions. This could have resulted in underrepresentation of substance use. The small number of participants in this study limits the generalisability of the findings. It would be valuable to expand this study to other healthcare professions students at this institution, as well as to other institutions across South Africa.

\section{Conclusion}

The high self-reported use of alcohol, drugs and cigarette and water pipe smoking among second and third year undergraduate medical students in this study is of great concern. Prevention, early identification and remediation of risky behaviour of future healthcare professionals should be an urgent priority.

\section{Recommendations}

This study emphasises the need for follow-up studies to identify and address the driving factors responsible for the concerning prevalence of alcohol and drug use among medical students. Additionally, a holistic approach that includes prevention, early identification and emotional as well as social support programmes must be developed and incorporated in the curriculums of health sciences students.

The focus for alcohol and drug abuse prevention programmes should rather be on social and enhancement motives that resonate more with university students than emphasising the negative consequences of alcohol and drug use.

\section{Acknowledgements}

The authors wish to acknowledge all second and third year medical students from the Faculty of Health Sciences, University of the Free State (UFS), who participated in the study. The administrative staff and Ms S. Roux, Department of Medical Sciences, UFS, are acknowledged for their support with data capturing. The authors also wish to acknowledge Ms T. Mulder, School of Medicine, UFS, as medical editor for assistance with manuscript preparation.

\section{Competing interests}

The authors declare that they have no financial or personal relationship(s) which may have inappropriately influenced them in writing this article.

\section{Authors' contributions}

All authors were involved in the planning, protocol preparation, data interpretation and publication planning, writing, editing and finalisation of the article. Except for the above-mentioned factors, A.M.G. and A.V. were also responsible for the data collection and analysis.

\section{Funding information}

This research received no specific grant from any funding agency in the public, commercial or not-for-profit sectors.

\section{Data availability statement}

Data sharing is not applicable to this article as no new data were created or analysed in this study.

\section{Disclaimer}

The views and opinions expressed in this article are those of the authors and do not necessarily reflect the official policy or position of any affiliated agency of the authors.

\section{References}

Arora, A., Kannan, S., Gowri, S., Choudhary, S., Sudarasanan, S. \& Khosla, P.P., 2016, 'Substance abuse amongst the medical graduate students in a developing country', Indian Journal of Medical Research 143(1), 101-103. https://doi.org/ 10.4103/0971-5916.178617

Borsari, B. \& Carey, K.B., 2001, 'Peer influences on college drinking: A review of the research', Journal of Substance Abuse 13(4), 391-424. https://doi.org/10.1016/ S0899-3289(01)00098-0

Bucher, J.T., Vu, D.M. \& Hojat, M., 2013, 'Psychostimulant drug abuse and personality factors in medical students', Medical Teacher 35(1), 53-57. https://doi.org/10.31 09/0142159X.2012.731099

Bucholz, K.K., Cadoret, R., Cloninger, C.R., Dinwiddie, S.H., Hesselbrock, V.M., Nurnberger, J.I. et al., 1994, 'A new, semi-structured psychiatric interview for use in genetic linkage studies: A report on the reliability of the SSAGA', Journal of Studies on Alcohol 55(2), 149-158. https://doi.org/10.15288/jsa.1994.55.149

Budhathoki, N., Shrestha, M.K., Acharya, N. \& Manandhar, A., 2010, 'Substance use among third year medical students of Nepal', Journal of Nepal Health Research Council 8(16), 15-18

Center for Adolescent Substance Abuse Research, 2009, The CRAFFT screening tool, CeASAR, Boston, MA, viewed 17 July 2015, from http://www.ceasar-boston.org/ clinicians/crafft.php

Choi, D., Tolova, V., Socha, E. \& Samenow, C.P., 2011, 'Substance use and attitudes on professional conduct among medical students: A single-institution study', Academic Psychiatry 37(3), 191-195. https://doi.org/10.110.1176/appi. study', Academic
ap.12060126

Drugwatch, 2015, Student health, viewed 27 August 2016, from https://www. drugwatch.com/health/students/.

Emmons, K.M., Wechsler, H., Dowdall, G. \& Abraham, M., 1998, 'Predictors of smoking among US college students', American Journal of Public Health 88(1), 104-107. https://doi.org/10.2105/AJPH.88.1.104

Gerber, A.M., Botes, R. \& Vorster, L., 2016, 'An inferential comparison between the capabilities and achievements of 1st-year medical and nursing students at the University of the Free State, Bloemfontein, South Africa', African Journal of Health Professions Education 8(2), 200-202. https://doi.org/10.7196/AJHPE.2016. v8i2.719

Habibzadeh, A., Alizadeh, M., Malek, A., Maghbooli, L., Shoja, M.M. \& Ghabili, K., 2011, 'Illicit methylphenidate use among Iranian medical students: Prevalence and knowledge', Drug Design, Development and Therapy 5, 71-76. https://doi. org/10.2147/DDDT.S13818

Halme, J.T., Seppä, K., Alho, H., Pirkola, S., Poikolainen, K., Lönngvist, J. \& Aalto, M., 2008, 'Hazardous drinking: Prevalence and associations in the Finnish general population', Alcoholism, Clinical and Experimental Research 32(9), 1615-1622. https://doi.org/10.1111/j.1530-0277.2008.00740.x

Ialomiteanu, A.R. \& Adlaf, E.M., 2015, CAMH monitor 2014: Metadata user's eGuide, Centre for Addiction and Mental Health, Toronto, ON, viewed 07 August 2015, from https://www.camh.ca/en/research/news_and_publications/CAMH\%20Monitor/ CM2014_Metadata_eGuide.pdf.

Jackson, E.R., Shanafelt, T.D., Hasan, O., Satele, D.V. \& Dyrbye, L.N., 2016, 'Burnout and alcohol abuse/dependence among U.S. medical students', Academic Medicine 91(9), 1251-1256. https://doi.org/10.1097/ACM.0000000000001138

Jain, R., Chang, C., Koto, M., Geldenhuys, A., Nichol, R. \& Joubert, G., 2017, 'Non-medical use of methylphenidate among medical students of the University of the Free State', South African Journal of Psychiatry 23(1), a1006. https://doi. org/10.4102/sajpsychiatry.v23.1006

Johnston, L.D., O'Malley, P.M., Miech, R.A., Bachman, J.G. \& Schulenberg, J.E., 2015, Monitoring the future. National survey results on drug use, 1975-2015. Overview, key findings on adolescent drug use, Institute for Social Research,
University of Michigan, Ann Arbor, MI, viewed 27 August 2016, from http://www. monitoringthefuture.org/pubs/monographs/mtf-overview2015.pdf.

Leinwand, D., 2007, 'College drug use, binge drinking rise', USA Today, 15 March 2007 viewed 27 August 2015, from http://usatoday30.usatoday.com/news/nation/ 2007-03-15-college-drug-use_N.htm. 
Lejuez, C.W., Aklin, W.M., Jones, H.A., Richards, J.B., Strong, D.R., Kahler, C.W. et al. 2003, 'The Balloon Analogue Risk Task (BART) differentiates smokers and nonsmokers', Experimental and Clinical Psychopharmacology 11(1), 26-33. https://doi.org/10.1037/1064-1297.11.1.26

Levy, B. \& Earleywine, M., 2003, 'Reinforcement expectancies for studying predict drinking problems among college students: Approaching problem drinking from an expectancies choice perspective', Addictive Behaviors 28(3), 551-559. https:// doi.org/10.1016/S0306-4603(01)00250-7

Mayer, J. \& Filstead, W.J., 1979, 'The adolescent alcohol involvement scale. An instrument for measuring adolescents' use and misuse of alcohol', Journal of Studies on Alcohol 40(3), 291-300. https://doi.org/10.15288/ jsa.1979.40.291

Mesquita, A.M., Laranjeira, R. \& Dunn, J., 1997, 'Psychoactive drug use by medical students: A review of the national and international literature', Sao Paulo Medical Journal 115(1), 1356-1365. https://doi.org/10.1590/S1516-3180199 7000100007

National Institute on Alcohol Abuse and Alcoholism, n.d., Drinking levels defined, NIAAA, Bethesda, ML, viewed 15 November 2016, from https://www. niaaa.nih.gov/alcohol-health/overview-alcohol-consumption/moderate-bingedrinking.

National Institute on Alcohol Abuse and Alcoholism, 2006, Underage drinking. Why do adolescents drink, what are the risks, and how can underage drinking be prevented? Alcohol Alert, No. 67, NIAAA, Rockville, MD, viewed 07 August 2015, from http://pubs.niaaa.nih.gov/publications/AA67/AA67.htm.

National Institute on Drug Abuse, n.d., Drug facts. What is marijuana? viewed 27 August 2015, from https://www.drugabuse.gov/publications/drugfacts/ marijuana.

O'Flynn, N., 2011, 'Harmful drinking and alcohol dependence: Advice from recent NICE guidelines', British Journal of General Practice 61(593), 754-756. https://doi. org/10.3399/bjgp11X613287

Padrão, P., Lunet, N., Santos, A.C. \& Barros, H., 2007, 'Smoking, alcohol, and dietary choices: Evidence from the Portuguese National Health Survey', BMC Public Health 7, 138. https://doi.org/10.1186/1471-2458-7-138

Peltzer, K., Davids, A. \& Njuho, P., 2011, 'Alcohol use and problem drinking in South Africa: Findings from a national population-based survey', African Journal of Psychiatry 14(1), 30-37. https://doi.org/10.1176/appi.ap.12060126
Retief, M. \& Verster, C., 2016, 'Prevalence and correlates of non-medical stimulants and related drug use in a sample of South African undergraduate medical students', South African Journal of Psychiatry 22(1), a795. https://doi.org/ 10.4102/sajpsychiatry.v22i1.795

Rigotti, N.A., Lee, J.E. \& Wechsler, H., 2000, 'US college students' use of tobacco products: Results of a national survey', Journal of the American Medical Association 248(6), 699-705.

SA Statistics, 2013, Addiction statistics, viewed 27 August 2015, from https:// christiandrugsupport.wordpress.com/most-commonly-used-drugs/sa-statistics/.

Seggie, J., 2012, 'Alcohol and South Africa's youth', South African Medical Journal 102(7), 587. https://doi.org/10.7196/SAMJ.6003

Steyn, F., 2016, 'Methylphenidate use and poly-substance use among undergraduate students attending a South African university', South African Journal of Psychiatry 22(1), a760. https://doi.org/10.4102/sajpsychiatry.v22i1.760

United Nations Office on Drugs and Crime, 2013, World drug report 2013, United Nations Publications, Vienna, Austria, viewed 07 August 2015, from https://www. unodc.org/unodc/secured/wdr/wdr2013/World_Drug_Report_2013.pdf.

Van Heerden, M.S., Grimsrud, A.T., Seedat, S., Myer, L., Williams, D.R. \& Stein, D.J., 2009, 'Patterns of substance use in South Africa: Results from the South African Stress and Health study', South African Medical Journal 99(5 Pt 2), 358-366.

Van Zyl, P., Botha, J., Van Wyk, M., Breytenbach, J., Nelm C., Van Niekerk, M. et al., 2015, 'Hazardous, harmful and dependent drinking in hostel-dwelling students a the University of the Free State, Bloemfontein: A cross-sectional study', Journal of Child \& Adolescent Mental Health 27(2), 125-133. https://doi.org/10.2989/1728 0583.2015.1084310

Webb, J.R., Valasek, M.A. \& North, C.S., 2013, 'Prevalence of stimulant use in a sample of US medical students', Annals of Clinical Psychiatry 25(1), 27-32.

Wechsler, H., Davenport, A., Dowdall, G., Moeykens, B. \& Castillo, S., 1994, 'Health

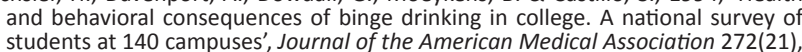
1672-1677. https://doi.org/10.1001/jama.1994.03520210056032

Welcome, M.O., Mastorakis, N.E., Razvodovsky, Y.E., Pereverzeva, E.V. \& Pereverzev, V.A., 2015, 'Relationship between alcohol consumption and academic success of medical students in Minsk, Belaus', in N.E. Mastorakis \& I. Corbi (eds.), Advances in environmental science and energy planning, pp. 235-244, WSEAS Press, Canary Islands, Spain. 